\title{
Análise das Práticas de Governança Eletrônica dos Municípios mais Populosos do Brasil: Um Estudo Baseado no Modelo de Mello (2009)
}

\section{Analysis of Electronic Governance Practices of Municipalities most Populous of Brazil: A Study Based on Model de Mello (2009)}

\section{Análisis de las Prácticas de Gobernancia Electrónica de Municipios más Pobladas de Brasil: Un Estudio Basado en Modelo de Mello (2009)}

Fábia Jaiany Viana de Souza, Me. Contadora do Instituto Federal de Educação, Ciência e Tecnologia do Rio Grande do Norte. Endereço Profissional: Av. José Rodrigues de Aquino Filho, 640, Alto de Santa Luzia, CEP: 59215-000, Nova Cruz/RN, Telefone: (84) 40054107. E-mail: fabiajaiany@yahoo.com.br

Aneide Oliveira Araújo, $\mathrm{Dr}^{\mathrm{a}}$ Professora da Universidade Federal do Rio Grande do Norte. Endereço Profissional: Av. Senador Salgado Filho, s/n, Campus Universitário, Lagoa Nova, CEP 59072-970, Natal/RN, Telefone: (84) 3215-3486. e-mail: aneide@ufrnet.br
Fábio Resende de Araújo, Me.

Doutorando em Administração pela Universidade Federal do Rio Grande do Norte. Professor da Universidade Federal do Rio Grande do Norte. Endereço Profissional: Rua Trairi, s/n, Centro, CEP: 59200-000, Santa Cruz/RN, Telefone: (84) 32912411. e-mail: resende araujo@hotmail.com

Maurício Corrêa da Silva, Me. Doutorando em Ciências Contábeis (UnB/UFPB/UFRN). Professor da Universidade Federal do Rio Grande do Norte. Endereço Profissional: Av. Senador Salgado Filho, s/n, Campus Universitário, Lagoa Nova, CEP 59072-970, Natal/RN, Telefone: (84) 3215- 3486. e-mail: prof.mauriciocsilva@gmail.com

RESUMO

Esta pesquisa tem como objetivo geral analisar as práticas de governança eletrônica dos 100 municípios mais populosos do Brasil, a partir do modelo proposto por Mello (2009). Para atingir esse objetivo, a metodologia utilizada foi a descritiva, bibliográfica e documental. Os resultados revelaram que prática de usabilidade e acessibilidade foi aquela que apresentou a maior média de implantação entre os municípios com média de 11,40, seguido pela prática de conteúdo com 11,13. Além disso, constatou-se que Campo Grande foi o município com maior pontuação para o IGMB, com $64,30 \%$ das práticas de governança eletrônica implantadas, seguido por Anápolis (62,83\%), Vitoria (62,47\%), Betim (62,01।\%) e São Paulo com (61,02\%) das práticas observadas nos sítios. Boa Vista foi aquele com a menor pontuação para o IGMB, com $18,76 \%$ das práticas de governança eletrônica implantadas. Conclui-se que os municípios pesquisados não estão implantando as práticas de governança que são discutidas na literatura, o que torna claro que tais municípios necessitam observar que apenas a implantação das tecnologias da informação sem um incentivo a participação da sociedade, não garante uma interação entre governo e sociedade, dificultando um canal de comunicação bilateral que promova um eficaz controle social.

Palavras-chave: Práticas. Governança Eletrônica. Municípios.

ABSTRACT

This research has as main objective to analyze the electronic governance practices of the 100 most populous municipalities of Brazil , from proposed by Mello (2009) model. To achieve this goal, the methodology used was descriptive and documentary bibliographical. The results revealed that the practice of usability and accessibility was the one that had the highest average deployment among municipalities with an average of 11,40, followed by 11,13 with practical content. Furthermore, it was found that Campo Grande was the municipality with the highest score for IGMB , with $64.30 \%$ of implanted electronic governance practices followed by Anápolis (62.83\%), Vitoria (62.47\%), Betim $(62.01 \%)$ and São Paulo with (61.02\%) of the practices observed at the sites. Boa Vista was the one with the lowest score for IGMB, with $18.76 \%$ of implanted electronic governance practices. It is concluded that the municipalities surveyed are not deploying governance practices that are discussed in the literature, which makes clear that the municipalities need only observe that the implementation of information technologies without an incentive to participate in society, does not guarantee an interaction between government and society, by making a two-way communication channel to promote effective social control. 
RESUMEN

Esta investigación tiene como objetivo principal analizar las prácticas de gobernancia electrónica de las 100 ciudades más pobladas del Brasil, a partir de propuestas por Mello modelo (2009). Para lograr este objetivo, la metodología utilizada fue de tipo descriptivo y bibliográfico y documental. Los resultados revelaron que la práctica de la usabilidad y la accesibilidad fue el que tuvo el despliegue más alto promedio entre los municipios con un promedio de 11,40, seguido por 11,13 con un contenido práctico. Por otra parte, se encontró que Campo Grande fue el municipio con la puntuación más alta para IGMB, con $64,30 \%$ de las prácticas de gobernancia electrónica implantada seguido de Anápolis (62,83\%), Vitoria (62,47\%), Betim (62.01\%) y São Paulo con (61.02\%) de las prácticas observadas en los sitios. Boa Vista fue el que tiene la puntuación más baja para IGMB, con $18,76 \%$ de las prácticas de gobernancia electrónica implantada. Se concluye que los municipios encuestados no están implementando prácticas de gobernancia que se discuten en la literatura, lo que hace evidente que los municipios sólo necesitan observar que la aplicación de tecnologías de la información sin un incentivo para participar en la sociedad, no garantiza una interacción entre gobierno y la sociedad, haciendo un canal de comunicación de dos vías para promover el control social efectivo.

Palabras clave: Prácticas. Gobernancia Electrónica. Municípios.

\section{INTRODUÇÃO}

Os administradores públicos têm realizado suas ações em um contexto complexo e precisam adaptar-se as novas realidades inseridas a cada dia na sociedade. Com o surgimento da globalização e da era do conhecimento, na qual é embasada a sociedade da informação, observa-se que as tecnologias de informação e comunicação (TIC), tornaram-se elementos fundamentais na maneira do Estado realizar suas principais funções. Essas tecnologias levam em consideração que a sociedade quer ter acesso ao governo de modo cada vez mais rápido e facilitado, o que passou a modificar a atuação da gestão pública (MEDEIROS, 2004).

A Sociedade da Informação está embasada nas TICs e nas ações que envolvem a aquisição, o armazenamento, o processamento e a disponibilização de informação através de meios eletrônicos. Essas tecnologias não promovem transformações na população por si só, no entanto, são usadas pela sociedade em seus contextos sociais, econômicos e políticos, passando a constituir a Sociedade da Informação, que corresponde a uma nova comunidade local que vem surgindo no mundo globalizado.

Diante disso, diversas mudanças de paradigmas ocorridas nas últimas décadas do século $\mathrm{XX}$, ocasionaram uma reestruturação econômica que transformou o modelo de desenvolvimento industrial em um modelo informacional. Essas mudanças também afetaram toda a sociedade que passou a se adaptar e aprendeu a conviver com esse novo cenário em que foi inserida. Foi nesse contexto, que as reformas administrativas dos estados ocorreram, com a finalidade de modernizar e flexibilizar as instituições públicas.

As discussões que envolvem essas reformas giram em torno de ações que apresentam como prioridade a prestação dos serviços públicos, especialmente, o seu acesso e a sua utilização, os quais podem ser melhor desenvolvidos com o uso de TIC. Essa situação pode desencadear, por consequência, uma melhor participação da população na gestão da Administração Pública (MEDEIROS, 2004).

Segundo Silva e Moreira (2006), a Internet já marcou seu espaço como ferramenta de comunicação na Administração Pública, entretanto, é fundamental que 
os governantes públicos disponibilizem informações que possibilitem a participação da sociedade através do controle social e adotem mecanismos que assegurem a acessibilidade informacional. A governança eletrônica pode ser considerada como uma parte da boa governança, permitindo o desenvolvimento da participação popular e da accountability (MELLO, 2009).

A governança eletrônica pode ser conceituada como a atuação dos cidadãos junto ao governo das comunidades em que estão inseridos por meios eletrônicos, de modo que se permita que esses indivíduos tenham liberdade para se manifestar sobre a Administração Pública. Segundo Mello (2009), a governança eletrônica não se refere, apenas, a disponibilização de serviços on-line ou a uma Administração Pública mais eficiente. O canal aberto pelas TIC possibilita um desenvolvimento muito maior na Administração Pública, em virtude dela ter por finalidade o aumento da participação da sociedade no controle das ações governamentais.

As práticas de governança eletrônica dos estados brasileiros e do Distrito Federal foram avaliadas por Mello (2009), ao propor em sua tese o Índice de Governança Eletrônica dos Estados Brasileiros (IGEB). A pesquisa avaliou que no período de 18 a 28 de fevereiro de 2009, o Estado de São Paulo já havia implantado $71,40 \%$ das práticas sugeridas e que o Estado do Mato Grosso do Sul havia implantado apenas $37,31 \%$. O referido autor fez recomendações de estudos sobre a implantação de novas práticas de governança eletrônica, bem como a sua utilização nos municípios brasileiros.

Diante desse contexto, da relevância do tema e da disponibilidade de dados para os municípios brasileiros com relação aos portais eletrônicos, o presente estudo busca responder o seguinte problema: Quais são as práticas de governança eletrônica dos 100 municípios mais populosos do Brasil, a partir do modelo proposto por Mello (2009)? Para responder esse problema, tem como objetivo geral analisar as práticas de governança eletrônica dos 100 municípios mais populosos do Brasil, a partir do modelo proposto por Mello (2009).

Para a realização do presente estudo, utilizou-se o modelo proposto por Mello (2009), em virtude desse modelo ser formado por um conjunto de variáveis que o permite englobar cinco âmbitos de categorias de análise da governança eletrônica, $\mathrm{o}$ que o torna um modelo relevante para essa área de conhecimento, por ser dentre os modelos existentes, aquele com maior abrangência de análise de variáveis e o mais recente modelo desenvolvido com essa temática.

Visualiza-se a relevância de pesquisas sobre essa temática, uma vez que permitem a reflexão de gestores públicos, usuários e estudiosos de áreas afins sobre a importância da governança eletrônica na Administração Pública. Nessa perspectiva, esse estudo pretende apresentar as práticas de governança eletrônica que estão sendo adotadas, de modo que seja possível realizar um mapeamento da atual situação da governança eletrônica nos municípios pesquisados, com a perspectiva de contribuir com o aperfeiçoamento desses sítios, o que poderá facilitar a relação entre governantes públicos e sociedade. 
O artigo apresenta, além dessa seção de introdução, o embasamento do estudo, constituído da apresentação dos conceitos da literatura existentes acerca do tema, o método de pesquisa que norteará o estudo, a análise e discussão dos resultados, e, por fim, as considerações finais.

\section{FUNDAMENTAÇÃO TEÓRICA}

Esta seção apresenta o embasamento do estudo do estudo, para isso, discorre, inicialmente, sobre a governança eletrônica, e, em seguida, sobre suas práticas.

\subsection{Governança Eletrônica}

Os administradores públicos, nos últimos anos, vêm buscando ferramentas que permitam a interação entre serviços públicos e sociedade, em virtude de cada vez mais se exigir dos governantes uma gestão mais eficaz e transparente. Segundo explicação de Gomes (2005), as Tecnologias de Informação e Comunicação (TICs) transformaram-se em um dos elementos mais relevantes de articulação das atividades operacionais dos governos, aperfeiçoando a disponibilização de informações e a prestação de serviços à sociedade.

As TICs possibilitam um governo mais estreito entre governantes e cidadãos, ao mesmo tempo, possibilitam que a população passe a ter contato com ferramentas que a permite interferir nas decisões governamentais por meio dos sítios eletrônicos (CHADWICK, 2003). A aplicação dos recursos dessas tecnologias na Administração Pública é conhecida como a governança eletrônica ou e-governança.

A governança enfatiza uma nova forma de visualizar a Administração Pública e a gestão de políticas públicas, tendo em vista que "governar torna-se um processo interativo porque nenhum ator detém sozinho o conhecimento e a capacidade de recursos para resolver problemas unilateralmente" (STOKER, 2000, p. 93).

Nessa perspectiva, a e-governança passa a contar com três elementos constituintes: a tecnologia, os indivíduos e a Administração Pública. Não se relacionado apenas com a administração da tecnologia, mas também, com a gestão das instituições, uma vez que sempre existirá a criação de serviços de Internet nas cidades, proporcionando a distribuição de informações e permitindo um maior nível de comunicação com a população. (FREY, 2000).

O conceito de governança eletrônica é mais abrangente que o de governo eletrônico, tendo em vista que pode influenciar o modo como os governos e a sociedade referem-se uns aos outros. Já o governo eletrônico corresponde a oferta de informações e serviços através de meios eletrônicos (UNESCO, 2005). De acordo com essa mesma fonte, sua principal finalidade é melhorar a boa governança, uma vez que a utilização das TICs pode proporcionar o aumento da participação cidadã, envolvendo os governantes na oferta de melhores serviços em termos de tempo, 
podendo ter custos de transação mais baixos e serviços públicos mais acessíveis (MELLO, 2009).

Conforme discutido por Paul (2007), a governança incentiva as relações intergovernamentais, otimizando a formulação de políticas mais eficientes, eficazes, efetivas, sustentáveis e transparentes. Além disso, Mello (2009) discorre que ela pode ser considerada uma ferramenta de controladoria, em virtude de permitir que a população possa ter contato com informações e serviços públicos, possibilitando a prestação de serviços e informações do governo público, utilizando ferramentas eletrônicas e permitindo que o governo possa se relacionar com a sociedade e servindo como um incentivo a mudança social.

Assim, discute-se que a governança eletrônica refere-se a forma como se conduz uma sociedade para que se possa atingir seus objetivos, sendo a participação popular uma das responsáveis por proporcionar uma mudança interna no aparato estatal e uma reorganização entre Estado e cidadãos. Entretanto, a melhor forma de oferecer serviços públicos a sociedade não possibilita necessariamente uma reestruturação do Estado.

As estratégias que envolvem a governança eletrônica apenas permitirão um aperfeiçoamento real dos serviços públicos se passarem a ser observados no contexto da reforma da Administração Pública. Por consequência, se espera que de um lado se tenha a necessidade da adaptação das atividades e dos processos administrativos ao formato da era digital, e por outro lado, a definição de novos conceitos de governança, que priorizem o desenvolvimento de redes sociais e parcerias públicas, ao contrario da abordagem burocrática tradicional (SAMPAIO, 2009).

Salienta-se, ainda, que não é necessária apenas a disponibilização de ferramentas online para participação da sociedade. É fundamental que elas sejam capazes de influenciar as decisões dos governantes e que tenham efeitos que possam ser observados no planejamento e desenvolvimento das políticas públicas (FREY, 2000; JARDIM, 2007; RUEDIGER, 2002).

De acordo com Sampaio (2009), a governança eletrônica desejável é aquela que promove mudanças no Estado em três aspectos principais: é necessário que o governo permita a interação da sociedade em seu processo de tomada de decisões; que possibilite a consulta de informações e o monitoramento das atividades do governo e a realização de discussões públicas; e, por fim, é imprescindível a participação popular na gestão pública.

No Brasil, diversos autores (FREY, 2000; GOMES, 2005, RUEDIGER, 2002) observaram em seus estudos que existe o predomínio de portais eletrônicos governamentais que apenas oferecem serviços públicos a população, com ambientes informativos superficiais, sem a presença de ferramentas que estimulem a participação da sociedade na gestão governamental.

Dessa forma, os portais do governo apresentam mais características de governo eletrônico e ainda se encontram longe de uma governança eletrônica que seja capaz de reestruturar o Estado e permitir novas formas de interação entre 
governantes e os cidadãos, pois falta o incentivo a participação popular nas decisões do governo, que corresponde a peça fundamental de uma boa governança eletrônica.

Dessa forma, observa-se que o avanço da tecnologia não deve ser visualizado apenas por meio da disponibilização de serviços online, mas também, por ser responsável pelo desenvolvimento da interação entre governo e sociedade e por demonstrar a cada dia a necessidade da implantação da transparência pelos governantes públicos. Em resumo, as TIC são as responsáveis pelo desenvolvimento da governança eletrônica e pelos seus dois itens básicos, governo eletrônico e democracia eletrônica. Desse modo, elas exercem um importante papel democrático, uma vez que possibilitam uma melhor atuação da sociedade no controle social dos atos públicos.

\subsection{Práticas de Governança Eletrônica}

A pesquisa de Holzer e Kim (2005), que teve a finalidade de formular um índice de governança eletrônica para avaliar as websites das cem maiores cidade do mundo, serviu de base para o estudo de Mello (2009), o qual será adotado nessa pesquisa. A estrutura adotada por Holzer e Kim (2005) considera que a governança eletrônica, engloba o governo eletrônico (prestação de serviços públicos) e a democracia eletrônica (participação cidadã no governo) e que esses dois são representados por cinco subgrupos de práticas: conteúdo, serviços, participação cidadã, privacidade e segurança e usabilidade e acessibilidade.

As práticas de conteúdo são classificadas por Holzer e Kim (2005) em cinco áreas: acesso a informações de contato, documentos públicos, informações sensíveis e materiais multimídia. As práticas de serviços podem ser classificadas em serviços que possibilitam que a população interaja com o governo (instrumentos que permitam a consulta de informações, acesso a informações sobre educação, indicadores econômicos, instituições educacionais, meio ambiente, saúde, ferramentas para possíveis denúncias, disponibilização de informações sobre políticas púbicas etc.) e serviços que permitam que a sociedade possa registrar-se nos eventos e nos serviços (pagamentos de tributos, concessão de licenças, certidões ou permissões, pregoes eletrônicos etc.).

Com reação a prática de participação cidadã, Holzer e Kim (2005) explicam que ela refere-se à existência de ferramentas que permitam contato online dos cidadãos com os gestores púbicos, incentivando a participação popular em decisões de orçamento e planejamento e a possibilidade da realização de criticas e sugestões sobre temas diversos.

Mello (2009) explica que os sítios devem possuir práticas de privacidade e segurança, apresentando confidencialidade e segurança na transmissão dos dados, devendo as informações disponibilizadas nos sítios serem protegidas contra acesso a manipulação e uso indevido, tendo em vista que se os usuários verificarem 
segurança nos portais eletrônicos preferirão interagir com os governantes por meio eletrônico.

Por fim, esse mesmo autor, ainda discute que os portais eletrônicos devem ser construídos de modo que aqueles usuários que não estejam familiarizados com tais sítios, possam facilmente encontrar as informações que busquem nos portais e consigam realizar todas as ações referentes a governança eletrônica, o que corresponde a finalidade da prática de usabilidade e acessibilidade.

\section{PROCEDIMENTOS METODOLÓGICOS}

Raupp e Beuren (2012) sugerem que a pesquisa seja delineada quanto aos objetivos, procedimentos e abordagem do problema. Quanto aos objetivos, este estudo é caracterizado como pesquisa descritiva. Com relação aos procedimentos, foi realizada uma pesquisa bibliográfica e documental. Quanto à discussão sobre o problema esse estudo é caracterizado como sendo qualitativo.

O universo deste estudo são todos os municípios brasileiros. Por conveniência foi realizada uma amostra composta somente dos 100 municípios mais populosos do Brasil. Os sítios oficiais foram obtidos através do "google". Caso não tivessem nos sítios oficiais (página principal), as informações a respeito das variáveis de análises, uma nova busca era realizada para verificar se existia em outro órgão da administração pública do município pesquisado que permitisse a consulta das informações relacionadas às práticas de governança eletrônica.

A coleta de dados foi desenvolvida durante o período de 01 de junho a 30 de agosto de 2013. Após a coleta de dados, as informações coletadas foram trabalhadas em planilhas do Microsoft Excel com a finalidade obter o Índice de Governança Eletrônica das Municípios Brasileiras (IGMB), com base nas variáveis e análises de dados propostos por Mello (2009), a seguir discriminados.

O Quadro 1 apresenta as variáveis utilizadas para analisar a governança eletrônica. As mesmas foram divididas em cinco grupos: conteúdo (PCon), serviços (PSer), participação cidadã (PPC), privacidade e segurança (PPS) e usabilidade e acessibilidade (PUA).

\begin{tabular}{|l|l|l|}
\hline Práticas & \multicolumn{2}{|c|}{ Itens analisados } \\
\hline & - Lista de links de órgãos & - Apresentação compreensível dos \\
& internos e externos & documentos públicos (linguagem \\
& - Agenda do gestor & - Gestão de emergências \\
Conteúdo & - Códigos e regulamentos & - Oferta de emprego e treinamentos \\
$(13$ itens) & - Orçamento, anexos da LRF e & - Calendário de eventos \\
& licitações & - Responsável pela atualização da \\
& - Cargos, competências e & página \\
& salários dos servidores & - Arquivos de áudio e vídeo \\
& - Concursos públicos & \\
\hline
\end{tabular}




\begin{tabular}{|c|c|c|}
\hline $\begin{array}{l}\text { Serviço } \\
\text { (16 itens) }\end{array}$ & $\begin{array}{l}\text { - E-mail, telefones e endereços } \\
\text { - Página principal } \\
\text { personalizada } \\
\text { - Uso de senhas } \\
\text { - Educação, indicadores } \\
\text { econômicos e instituições } \\
\text { educacionais } \\
\text { - Responsável pelo sítio } \\
\text { - Relatório das violações das } \\
\text { leis e regulamentos } \\
\text { - Mecanismo para queixas e } \\
\text { denúncias } \\
\text { - Notícias sobre políticas } \\
\text { públicas } \\
\text { - Preenchimento de guias, } \\
\text { cálculo de tributos e } \\
\text { pagamento online }\end{array}$ & $\begin{array}{l}\text { - Dados cadastrais, legislação, } \\
\text { débitos de veículo, emissão de } \\
\text { guias e programas de educação de } \\
\text { trânsito } \\
\text { - Consultas e certidões tributárias, } \\
\text { nota fiscal eletrônica } \\
\text { - Registro do cidadão/ empresa } \\
\text { para serviços online } \\
\text { - Licença sanitária, licença para } \\
\text { abrir e fechar estabelecimentos, } \\
\text { permissão para construção } \\
\text { - Compra de bilhetes para eventos } \\
\text { - Compras eletrônicas (pregão) } \\
\text { - Editais e resultados das licitações }\end{array}$ \\
\hline $\begin{array}{c}\text { Participação Cidadã } \\
\text { (10 itens) }\end{array}$ & $\begin{array}{l}\text { - Boletim informativo online } \\
\text { - Informações de governança } \\
\text { - E-mail para contato, política e } \\
\text { prazo para resposta e uma } \\
\text { cópia da mensagem original } \\
\text { - Quadro de anúncios, bate- } \\
\text { papo, grupos de discussão e } \\
\text { chats. } \\
\text { - Agenda de reuniões }\end{array}$ & $\begin{array}{l}\text { - Pesquisas da percepção do } \\
\text { cidadão sobre os serviços prestados } \\
\text { e sobre governança eletrônica } \\
\text { - Canal para denúncias } \\
\text { - E-mail, telefone, endereço para } \\
\text { contato com os gestores } \\
\text { - Estruturas e funções da capital } \\
\text { - Link de democracia ou } \\
\text { participação cidadã na página } \\
\text { principal }\end{array}$ \\
\hline $\begin{array}{c}\text { Privacidade e } \\
\text { Segurança (8 itens) }\end{array}$ & $\begin{array}{l}\text { - Política de privacidade do } \\
\text { sítio } \\
\text { - Possibilidade de entrar e sair } \\
\text { do fornecimento de } \\
\text { informações } \\
\text { - Usuário possa contestar as } \\
\text { informações erradas ou } \\
\text { incompletas } \\
\text { - Práticas de qualquer } \\
\text { informações coletadas }\end{array}$ & $\begin{array}{l}\text { - Uso de senhas, criptografia de } \\
\text { dados sensíveis e procedimentos de } \\
\text { auditoria } \\
\text { - Contato para críticas e denúncias } \\
\text { - Informações públicas através de } \\
\text { área restrita } \\
\text { - Informações não públicas através } \\
\text { de área restrita }\end{array}$ \\
\hline $\begin{array}{l}\text { Usabilidade e } \\
\text { Acessibilidade } \\
\quad \text { (19 itens) }\end{array}$ & $\begin{array}{l}\text { - Homepage de no máximo dois } \\
\text { comprimentos da tela } \\
\text { - Público alvo com canais } \\
\text { personalizados } \\
\text { - Barra de navegação com itens } \\
\text { claros que tornem a navegação } \\
\text { mais fácil } \\
\text { - Links para a página inicial em } \\
\text { todas as páginas, para os } \\
\text { departamentos da capital e } \\
\text { para os sítios relacionados fora } \\
\text { da capital } \\
\text { - Mapa do sítio }\end{array}$ & $\begin{array}{l}\text { - Documentos longos em pdf ou } \\
\text { doc } \\
\text { - Campos dos formulários sejam } \\
\text { acessíveis pelo cursor ou teclas, } \\
\text { indicação dos campos obrigatórios } \\
\text { - Informações de como identificar e } \\
\text { corrigir erros submetidos } \\
\text { - Link para busca } \\
\text { - Mecanismo de pesquisa em todo o } \\
\text { sitio } \\
\text { - Mecanismo de acesso aos } \\
\text { portadores de necessidades } \\
\text { especiais. }\end{array}$ \\
\hline
\end{tabular}




\begin{tabular}{|l|l|l|}
\hline & - Páginas com adequação de & - Conteúdo do sítio em mais de um \\
& estilos, fontes, formatação de & idioma \\
texto e visibilidade dos & - Textos escritos com fontes e cores \\
& elementos & adequados \\
- Textos sublinhados & - Conteúdo de áudio com legenda \\
& - Data da última atualização & - Acesso ao sítio por meio de \\
& das páginas & teclado \\
& - Link para informações sobre a \\
& capital & \\
\hline
\end{tabular}

Quadro 1 - Variáveis de análises das práticas de governança eletrônica

Fonte: adaptado do Apêndice 1 da tese de Mello (2009).

Foram estabelecidos pesos iguais para os subgrupos (conteúdo, serviços, participação cidadã, privacidade e segurança e usabilidade e acessibilidade) de 20 ou $20 \%$. Em seguida, tendo como base o número de práticas por subgrupo, foi estabelecida a pontuação de cada prática dentro do subgrupo, dividindo o peso atribuído para o subgrupo quantidade de práticas.

Por exemplo, o subgrupo serviços apresenta peso 20 e 16 itens de práticas analisadas, resultando em uma pontuação de 1,25 para cada prática consultada. Considerando o seguinte para aquelas práticas avaliadas na escala de 0-1: aquelas com resultado 0, prática não identificada, a pontuação é 0; e para aquelas com resultado 1, que significa que a prática foi adotada pela capital, a pontuação é 1,25. As práticas avaliadas na escala de 0-3 tiveram uma pontuação diferenciada por pesos. Assim, para aquelas com resultado 0 , prática não identificada, a pontuação é 0 , resultado 1 pontuação de 0,417 , o resultado 2 corresponde a pontuação de 0,833 e resultado de 3 , pontuação de 1,25 , que expressa pelo instrumento de pesquisa que a prática foi totalmente implantada.

Após a realização desses procedimentos para todas as 66 práticas de governança eletrônica somam-se todos os pontos obtidos por cada município nos cinco subgrupos (conteúdo, serviços, participação cidadã, privacidade e segurança e usabilidade e acessibilidade). Esse total de pontos representa o total de práticas de governança eletrônica implantadas pelos municípios em uma escala de 0 a 100, formando assim o IGCB.

\section{ANÁLISE E DISCUSSÃO DOS RESULTADOS}

Com base na consulta aos sítios dos municípios pesquisados e a partir da metodologia proposta por Mello (2009), foram obtidos os IGMB para os entes municipais que fizeram parte da amostra do estudo. A Tabela 1 apresenta os 15 municípios com melhores IGMB, em ordem decrescente de pontuação, assim como, os resultados das práticas de cada categoria que compõe esse índice: 
Tabela 1 - Municípios com os quinze melhores IGMB

\begin{tabular}{ccc|ccc|c}
\hline Municípios & PCON & PSER & PPC & PPS & PUA & IGMB \\
\hline Campo Grande & 15,39 & 14,58 & 12,00 & 12,50 & 9,83 & 64,30 \\
Anápolis & 12,31 & 11,25 & 11,33 & 12,50 & 15,44 & 62,83 \\
Vitória & 12,82 & 10,83 & 10,00 & 15,83 & 12,99 & 62,47 \\
Betim & 15,89 & 9,17 & 10,67 & 10,83 & 15,44 & 62,01 \\
São Paulo & 14,87 & 17,50 & 10,67 & 5,00 & 12,99 & 61,02 \\
Fortaleza & 13,33 & 14,17 & 11,33 & 6,67 & 15,44 & 60,94 \\
Franca & 14,36 & 11,25 & 9,33 & 12,50 & 12,99 & 60,43 \\
Carapicuíba & 16,92 & 10,42 & 8,00 & 11,67 & 13,34 & 60,34 \\
Ribeirão das Neves & 12,82 & 10,00 & 11,33 & 10,00 & 15,09 & 59,24 \\
Olinda & 17,43 & 10,41 & 7,33 & 10,00 & 14,04 & 59,22 \\
Piracicaba & 18,46 & 10,00 & 7,33 & 10,00 & 13,34 & 59,13 \\
Campinas & 13,85 & 14,16 & 13,33 & 7,50 & 10,18 & 59,02 \\
Canoas & 13,84 & 12,50 & 11,33 & 7,50 & 13,69 & 58,87 \\
Maringá & 11,79 & 10,83 & 11,33 & 10,00 & 14,74 & 58,70 \\
Joinville & 12,82 & 10,42 & 9,33 & 10,00 & 15,80 & 58,36 \\
\hline
\end{tabular}

Fonte: Dados da pesquisa (2013).

Constata-se com a observação da Tabela 1, que, dentre os municípios pesquisados, Campo Grande foi aquele com maior pontuação para o IGMB, com $64,30 \%$ das práticas de governança eletrônica implantadas, seguido por Anápolis $(62,83 \%)$ e Vitoria $(62,47 \%)$. Esses resultados demonstram que o grupo com melhores IGMB apresenta pontuações muito próximas, o que pode ser analisado ao se comparar o percentual de práticas obtido pelo município com melhor índice $(64,30 \%)$ e aquele que apresentou o décimo quinto IGMB (58,36\%), fato que sinaliza que os portais desses quinze municípios apresentam estágios semelhantes de implantação da governança eletrônica.

No entanto, isso não implica dizer que tais municípios estão com bons níveis de governança eletrônica. Na verdade, verificaram-se portais que possuem baixos níveis de governança e que não se incentivam a participação do cidadão nas ações do governo. Essa é a principal característica da governança eletrônica, e, diante da conjuntura que foi observada, permite constatar que os municípios pesquisados estão mais próximos do governo eletrônico, uma vez que eles, em sua grande maioria, apenas disponibilizam informações e serviços a sociedade, sem em contrapartida, incentivar a participação da sociedade na gestão pública e no desempenho do controle social.

A Tabela 2 apresenta os 15 municípios com os IGMB mais baixos, em ordem crescente de pontuação, assim como, os resultados das práticas de cada categoria que constitui este índice:

Tabela 2 - Municípios com os quinze menores IGMB

\begin{tabular}{c|c|c|c|c|c|c}
\hline Municípios & PCON & PSER & PPC & PPS & PUA & IGBE \\
\hline
\end{tabular}




\begin{tabular}{ccccccc}
\hline Boa Vista & 4,62 & 3,75 & 0,00 & 5,83 & 4,56 & 18,76 \\
Jaboatão dos & & & & & & \\
Guararapes & 3,59 & 3,75 & 3,33 & 0,00 & 10,88 & 21,56 \\
Osasco & 5,13 & 5,84 & 3,33 & 2,50 & 4,91 & 21,71 \\
Belford Roxo & 4,62 & 2,08 & 2,00 & 6,67 & 9,48 & 24,84 \\
Feira de Santana & 10,77 & 2,92 & 4,00 & 0,00 & 7,72 & 25,41 \\
Niterói & 7,69 & 1,25 & 4,00 & 2,50 & 10,88 & 26,32 \\
Aparecida de Goiânia & 8,72 & 5,00 & 0,67 & 4,17 & 9,13 & 27,68 \\
Aracaju & 9,23 & 6,67 & 2,67 & 0,83 & 9,83 & 29,23 \\
Paulista & 7,18 & 5,83 & 8,00 & 0,00 & 8,42 & 29,44 \\
Belém & 6,16 & 6,67 & 4,67 & 2,50 & 9,48 & 29,47 \\
Santo André & 7,69 & 7,50 & 5,33 & 3,33 & 6,32 & 30,18 \\
Nova Iguaçu & 4,62 & 8,33 & 2,00 & 8,33 & 7,02 & 30,30 \\
Contagem & 13,33 & 4,59 & 6,67 & 0,00 & 5,97 & 30,55 \\
Mossoró & 3,59 & 4,17 & 2,67 & 10,00 & 10,53 & 30,95 \\
Caxias do Sul & 7,18 & 4,17 & 2,00 & 5,83 & 11,93 & 31,11 \\
\hline
\end{tabular}

Fonte: Dados da pesquisa (2013).

Através da análise da Tabela 2, verifica-se que, entre os municípios analisados na pesquisa, Boa Vista foi aquele com a menor pontuação para o IGMB, com 18,76\% das práticas de governança eletrônica implantadas, seguido por Jaboatão dos Guararapes (21,56\%), Osasco (21,71\%) e Belford Roxo (24,84\%). A partir da observação desses resultados, é possível constatar que esses municípios possuem poucas práticas de governança eletrônica implantadas e que existem diferenças significativas entre as práticas que são adotadas pelos municípios, o que evidencia que alguns municípios (Campo Grande, Anápolis e Vitoria) estão com estágios mais avançados de implantação de governança eletrônica do que outros (Boa Vista, Jaboatão dos Guararapes e Osasco). Essa situação pode ser exemplificada ao se comparar a pontuação dos municípios Campo Grande (64,30\%) e Boa Vista (18,76\%), que foram aqueles, respectivamente, com maior e menor IGMB.

O IGMB, como já mencionado anteriormente, leva em consideração a pontuação obtida em cada uma das cinco categorias de práticas governança analisadas na pesquisa, sendo relevante discutir os resultados de tais grupos de práticas individualmente.

Quando são analisadas as práticas de conteúdo, verifica-se que, entre os municípios pesquisados, aquele que apresentou o melhor desempenho foi Piracicaba com 18,46 pontos, seguido por Olinda $(17,43)$. Já Jaboatão dos Guararapes e Mossoró foram os municípios que obtiveram as pontuações mais baixas 3,59. Acrescentam-se essas informações, que a média de pontuação obtida pelos municípios para essa prática foi de 11,13 e que a pontuação máxima era 20 pontos.

No que se refere a informações de contato, constatou-se que não são todos os municípios que apresentam em seus portais eletrônicos a estrutura administrativa, assim como, o endereço e contato com horário de funcionamento, no entanto, deve se ressaltar que alguns municípios disponibilizam mais informações do que outros. Em 
sua maioria, os sítios não possuem agenda do gestor e políticas públicas, sendo que as noticias publicadas são dos acontecimentos passados. Além disso, somente algumas notícias divulgadas tem nome dos responsáveis pelas publicações. Em relação às informações das secretárias, existem informações de quem são os secretários, mas não de suas atribuições. Além disso, os portais dos municípios apresentam endereços de email gerais para contato, mas não, específicos de comunicação para com os secretários.

Quando é verificada a existência de documentos públicos nos sítios dos municípios pesquisados, constata-se que os portais disponibilizam links de acesso a documentos, mas em muitos casos, não era possível fazer o download dos documentos, apenas podia ser visualizado na tela. Os documentos mais disponibilizados nos sítios eram leis e regulamentos municipais, editais de licitação e informações sobre os orçamentos. Vale ressaltar, que a disponibilização a informações com essa natureza deve se tornar uma pratica constante dos órgãos públicos, possibilitando a sociedade o acesso não somente para consultá-los, mas também, que seja permitido fazer o download e copia dos documentos.

Com relação às informações sensíveis e a utilização de multimídia, observouse que os municípios pesquisados, em sua maioria, não disponibilizam em seus sites vídeos e áudios de eventos públicos e ou palestras, poucos são aqueles que apresentam quadro de anúncios, bate papo, chat para discutir questões políticas, econômicas, sociais com os gestores eleitos. Não possuem local específico para a gestão de emergências, não publicam suas páginas ofertas de emprego e envio de currículos.

Verificou-se que o melhor desempenho para as práticas de serviços foi de São Paulo com 17,49 pontos, seguido por Rio de Janeiro com $(14,58)$. Já Niterói foi o município que obtive a pontuação mais baixa, 1,21 pontos, seguidos por Belford Roxo e Feira de Santana. A média de pontuação obtida pelos municípios para essa prática foi de 8,46 .

Após analisar as práticas de serviços que são disponibilizadas pelos municípios, constatou-se que grande parte dos sítios analisados apresenta ferramentas que permitem a obtenção de certidões negativas, emissão de guias de tributos e mecanismos para encaminhamento de reclamações. Entretanto, deixam de disponibilizar a identificação do responsável pelo sitio para um posterior contato e informações a cerca de indicadores econômicos, educacionais ou sociais dos municípios, alem de não permitirem que os contribuintes façam simulações do calculo dos tributos, assim como, pagamentos online de tais valores.

Constatou-se que, entre os municípios pesquisados, aquele que apresentou o melhor desempenho para a prática de participação cidadã foi Campinas com 13,32 pontos, seguido por Natal $(12,66)$ e Guarulhos $(12,66)$. Já Boa Vista foi o município que obtive a pontuação mais baixa, 0 pontos, seguidos por Aparecida de Goiânia, Belford Roxo, Caxias do Sul e Nova Iguaçu, que também não tiveram um bom 
desempenho relativo a essa prática de governança eletrônica. A média de pontuação obtida pelos municípios para essa prática foi de 7,58.

Verificou-se que grande parte dos municípios pesquisados possuem sítios que não apresentam espaços específicos para que os usuários dos sítios possam reclamar ou sugerir melhorias para os sítios. Entretanto, cabe destacar, que muitos apresentam link referente a ouvidoria. Poucos são aqueles que possuem em suas páginas na internet boletins informativos ou agendas do gestor, quando disponibilizam tais itens são de ações pontuais da gestão. A presença de bate papo, chat, fórum para discutir questões políticas não foi observada nos municípios pesquisados.

Identificou-se que, entre os municípios pesquisados, aquele que apresentou o melhor desempenho para a prática de privacidade e segurança foi Vitória com 15,83 pontos, seguido por Rio de Janeiro $(15,83)$, Ponta Grossa $(14,16)$. Jaboatão dos Guararapes, Feira de Santana, Vila Velha, Contagem, Recife, Paulista e Belo Horizonte foram os municípios que obtiveram a pontuação mais baixa, 0 pontos, para essa prática de governança eletrônica. Acrescentam-se essas informações, que a média de pontuação obtida pelos municípios para essa prática foi de 7,01.

Após analisar as práticas de privacidade e segurança nos sítios dos municípios pesquisados, verificou-se que a grande maioria dos sítios não informam as praticas antes ou depois da coleta de informações, não evidenciando a entidade que esta recebendo a informação, o propósito da informação, os potenciais recebedores, a natureza da informação, os meios de coleta, entre outros. As informações públicas disponibilizadas nos sítios são de livre acesso, não necessitando de senhas ou assinaturas digitais para identificar os seus usuários e são poucos municípios que apresentam espaço destinado à consulta de informações não púbicas pelos servidores.

Constatou-se que, entre os municípios pesquisados, aquele que apresentou o melhor desempenho para a prática de usabilidade e acessibilidade foi Joinville e Londrina, com 15,79 pontos, seguido por Fortaleza $(15,44)$, Anápolis $(15,44)$ e São José dos Pinhais $(15,44)$. Já Boa Vista foi o município que obtive a pontuação mais baixa, 4,56 pontos, seguidos por Osasco e Contagem. A média de pontuação obtida pelos municípios para essa prática foi de 11,40.

Após analisar as práticas de usabilidade e acessibilidade nos sítios, verificouse que a maioria dos municípios apresentam páginas na internet que possuem um mapa ou esboço do site para a facilitação da localização das informações, assim como um espaço para a busca de informações no próprio sitio da prefeitura. Entretanto, constatou-se que não é disponibilizado nenhum mecanismo de acesso a informações por pessoas portadoras de necessidades especiais. Além disso, os sítios somente são disponibilizados em idioma português, não sendo visualizada nenhuma transcrição para outro idioma.

Observou-se que os gestores públicos dos municípios pesquisados têm exercido, em parte, a accountability, pois os mesmos vêm divulgando informações referentes às suas ações, no entanto, não as detalham no sentido de que a população 
possa avaliar as informações apresentadas nos demonstrativos, analisar o nível de sucesso resultante da gestão das finanças públicas e incentivar a participação da sociedade em audiências públicas no processo de elaboração e no curso da execução dos planos, da lei de diretrizes orçamentárias e dos orçamentos.

Entende-se a accountability como uma nova ferramenta de controle exercida da sociedade, a qual permite que a contabilidade possa propiciar o exercício do poder de escolha e tomada de decisão, menos enviesada possível, e demonstrar o exercício do dever de prestar contas do gestor público. Assim, espera-se que os municípios pesquisados possam aperfeiçoar a evidenciação de informações e que, também, insiram em seus portais eletrônicos ferramentas que incentivem a participação da sociedade na gestão pública, de modo que os cidadãos possam exercer o controle social.

Além disso, verificou-se que os municípios não estão implantando as práticas de governança que são discutidas na literatura, o que torna claro que tais municípios necessitam observar que apenas a implantação das tecnologias da informação sem um incentivo a participação da sociedade, não garante uma interação entre governo e sociedade, dificultando um canal de comunicação bilateral que promova um eficaz controle social.

Portanto, é indispensável que sejam inseridos mecanismos nesses sítios que incentivem a participação da população na gestão das atividades públicas, uma vez que os portais devem ser mais do que um meio para a disponibilização de serviços online, seria uma medida de capacitação política da sociedade, proporcionando uma maior participação da população no exercício da cidadania.

\section{CONSIDERAÇÕES FINAIS}

O estudo objetivou analisar as práticas de governança eletrônica dos 100 municípios mais populosos do Brasil, a partir do modelo proposto por Mello (2009). A pesquisa avançou a pesquisa base que foi realizada nos estados brasileiros, ao analisar as práticas de governança eletrônica no contexto municipal, servindo de mapeamento da atual situação da governança eletrônica nos municípios analisados, com a perspectiva de que seus resultados atuem como Benchmarking para cidades que não fizeram parte da amostra da pesquisa.

Recomendam-se outras pesquisas para que seja verificada como se encontra a governança eletrônica em outras amostras de estudo e no sentido de observar as causas que impossibilitam que a governança eletrônica seja implantada mais eficazmente pelos entes públicos, em virtude da relevância do tema, uma vez que ela torna mais transparente a forma de funcionamento do governo e possibilita aos diversos grupos da sociedade a capacidade de controlar com inteligência o Estado e permitindo um controle social mais atuante.

Os resultados revelaram que prática de usabilidade e acessibilidade foi aquela que apresentou a maior média de implantação entre os municípios com média de 
11,40, seguido pela prática de conteúdo com 11,13. Além disso, constatou-se que Campo Grande foi o município com maior pontuação para o IGMB, com 64,30\% das práticas de governança eletrônica implantadas, seguido por Anápolis (62,83\%), Vitoria $(62,47 \%)$, Betim $(62,01$ I \%) e São Paulo com $(61,02 \%)$ das práticas observadas nos sítios. Boa Vista foi aquele com a menor pontuação para o IGMB, com 18,76\% das práticas de governança eletrônica implantadas.

Conclui-se que os municípios pesquisados não estão implantando as práticas de governança que são discutidas na literatura, o que torna claro que tais municípios necessitam observar que apenas a implantação das tecnologias da informação sem um incentivo a participação da sociedade, não garante uma interação entre governo e sociedade, dificultando um canal de comunicação bilateral que promova um eficaz controle social. Portanto, é indispensável que sejam inseridos mecanismos nesses sítios que incentivem a participação da população na gestão das atividades públicas, uma vez que os portais devem ser mais do que um meio para a disponibilização de serviços online, seria uma medida de capacitação política da sociedade, proporcionando uma maior participação da população no exercício da cidadania.

Por fim, vale ressaltar, que somente a implantação das práticas de governança eletrônica não traduz plenamente o sentido de transparência na Administração Pública, pois existem outras práticas como a gestão de custos no Setor Público que também precisam ser levadas em consideração para uma Gestão Pública mais transparente e eficaz para a sociedade.

\section{REFERÊNCIAS}

CHADWICK, A. Bringing e-democracy back: why it matters for future research on egovernance. Social Science Computer Review, n. 21, 2003, p. 443-455.

FREY, K. Governança eletrônica: experiências de cidades européias e algumas lições para países em desenvolvimento. Revista IP - Informática Pública, Belo Horizonte, v. 2, mai. 2000, p. 31-48.

GOMES, W. A democracia digital e o problema da participação civil na decisão política. Revista Fronteiras - estudos midiáticos, v. 3, set./dez. 2005, p. 214-222.

HOLZER, M.; KIM, S. Digital Governance in Municipalities Worldwide (2005). Division for Public Administration and Development ManagementDepartment of Economic and Social Affairs, United Nations. 2005.

JARDIM, J. M. Governo eletrônico no Brasil: o portal rede governo. Arquivística. net, Rio de Janeiro, v. 3, n. 1, jan./jun. 2007, p. 28-37. 
MEDEIROS, P. H. R. Governo eletrônico no Brasil: aspectos institucionais e reflexos na governança. Dissertação de Mestrado. Programa de Pós-Graduação em Administração. Universidade de Brasília, Brasília, 2004. p.314.

MELLO, G. R. Estudo das práticas de governança eletrônica: instrumento de controladoria para a tomada de decisões na gestão dos estados brasileiros. 2009. Tese de Doutorado. Programa de Pós-Graduação em Curso de Ciências Contábeis. Universidade de São Paulo, São Paulo-SP, 2009, p.188.

PAUL, S. A case study of E-governance initiatives in India. The International Information \& Library Review.V.39, 2007, p. 176 -184.

RAUPP, F. M.; BEUREN, I. M. Metodologia da pesquisa aplicável as ciências sociais. In: BEUREN, Ilse Maria (org.) Como elaborar trabalhos monográficos em contabilidade: teoria e prática. 3. Ed. São Paulo: Atlas, 2012, p. 76-97.

RUEDIGER, M. A. Governo eletrônico e democracia: uma análise preliminar dos impactos e potencialidades na gestão PÚBLICA. Organizações \& Sociedade, Salvador, v.9 n.25, set./dez. 2002, p.29-43.

SAMPAIO, R. C. Governança eletrônica no brasil: limites e possibilidades introduzidos pelo orçamento participativo na internet. Planejamento e Políticas Públicas, n. 33, jul./dez.2009, p.123-144.

SILVA, L. M. da; MOREIRA, S. V. A Internet como instrumento de comunicação organizacional no setor público. UNIrevista, São Leopoldo, v. 1, n. 3, jul. 2006, p. 1432.

STOKER, G. Urban political science and the challenge of urban governance. In: Jon Pierre (Org.). Debating governance: authority, steering and democracy. New York: Oxford University Press, 2000, p. 91-109.

UNESCO - UNITED NATIONS EDUCATIONAL, SCIENTIFIC AND CULTURAL ORGANIZATION. Defining E -governance. 2005. Disponível em $<$ http://portalunesco.org. Acesso 19 ago.2013. 